\title{
Influence of biotic-abiotic factors on the degradation of novaluron in tropical soil
}

\author{
${ }^{1}$ P. Das; ${ }^{2 *}$ R. Pal; ${ }^{3}$ A. Chowdhury \\ ${ }^{1}$ Department of Agricultural Chemicals, Bidhan Chandra Krishi Viswavidyalaya, Mohanpur, West Bengal, \\ Pin- 741252, India \\ ${ }^{2}$ Department of Agricultural Chemistry and Soil Science, University of Calcutta, 35 Ballygunge \\ Circular Road, Calcutta, Pin-700019, India and Center for Environmental Risk Assessment and Remediation, \\ University of South Australia, Australia \\ ${ }^{3}$ Department of Agricultural Chemistry and Soil Science, University of Calcutta, 35 Ballygunge \\ Circular Road, Calcutta, Pin-700019, India
}

Received 12 April 2008; revised 1 May 2008; accepted 24 May 2008; available online 1 June 2008

\begin{abstract}
In this study, the degradation of novaluron (benzoylphenyl urea insect growth regulator) was investigated under controlled laboratory conditions in clay loam alluvial and coastal saline soils of West Bengal, India. The application rates were field rate (FR); $2 \mathrm{FR}$ and $10 \mathrm{FR}$. The incubation study was carried out at $30{ }^{\circ} \mathrm{C}$ and $60 \%$ of maximum water holding capacity of both the soils. Degradation of novaluron in both the soils followed first order reaction kinetics at all application rates under non-sterile and sterile conditions. The half-lives of novaluron in non-sterilized soils ranged from 17.0 - 17.8 days (alluvial soil) and 11.4 - 12.7 days (coastal saline soil), while the values in case of the sterilized soils were 53.7 - 59.0 days (alluvial soil) and 28.9-29.8 days (coastal saline soil) respectively. The novaluron degradation patterns were found to be highly influenced by soil types, application rates, and biotic abiotic factors. Abiotic factors strongly influenced novaluron degradation in both the soils. Biotic degradation was higher in alluvial soil compared to the coastal saline soil.
\end{abstract}

Key words: Pesticide, pest controlling agent, benzoylphenyl urea, sterile soil

\section{INTRODUCTION}

The indiscriminate use of broad spectrum synthetic pesticides has resulted in reduction of biodiversity, outbreak of secondary pests, development of pesticide resistance, pesticide-induced resurgence and contamination of food and the ecosystem (Singh, 2000). However, the use of synthetic pesticide as crop protection chemical cannot be fully substituted in modern agriculture for assured crop production. Enhancement of crop production can be achieved only by the application of new pesticides. Novaluron (Fig. 1), falling into the class of diflubenzoylureas, is a new pesticide molecule belonging to the group of insect growth regulators (IGR). Insect growth regulators are comparatively safer to beneficial insects as well as to the environment and are compatible for

X*Corresponding Author Email:p_raktim@rediffmail.com Tel.: +61 8830 25068; Fax: +618 83023057 use in integrated pest management. Thus, this compound is coming up as an eco-friendly or green pest-controlling agent. However, the effects of pesticide usage must be seen also in the context of soil pollution and sustainability of the agro-ecosystem. Increasing pesticide usage in agriculture adds to the rise in concern for the environmental contamination (Zhu et al., 2004). Pesticides reaching the soil may affect non-target soil microorganisms, thereby disturbing pesticide degradation processes ( $\mathrm{Pal}$ et al., 2006a). The overall dissipation of a pesticide from soil results from an interaction of biotic and abiotic mechanisms (Racke, et al., 1997). The pesticide degradation in soils depends largely on their physico-chemical properties and how they interact with the biotic and abiotic soil components (Beigel et al., 1999; Sannino et al., 1999). However, 


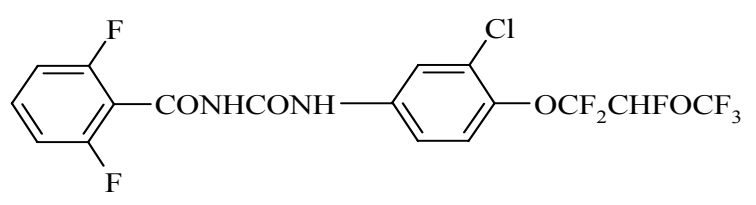

Fig. 1: Chemical structure of novaluron

the biotic mechanism has received much attention (Hafez and Thiemann, 2003). Numerous workers reported microbial degradation of pesticides in soil (Adhya et al., 1987; Banerjee et al., 1999; Karpouzas et al., 1999; Sukul and Spiteller, 2001; Hafez and Thiemann, 2003).

A detailed study of the available literatures revealed that the majority of the pesticide degradation studies were carried out in normal agricultural soils. However, there are a large part of arable soils, which are naturally or anthropogenically saline. Role of biotic and abiotic factors other than photodegradation in attenuating novaluron residues in soil was also studied. The higher rate of pesticide application to soil is recommended previously in laboratory studies (Sommerville, 1987). New pesticides are continuously being produced to control pest in intensive agriculture. In-depth studies of the effect of these newer pesticides on soil microbial activity and biomass seem pertinent before their release. The present investigation was carried out using novaluron [( \pm )-1-[3-chloro-4-(1,1,2-trifluoro-2-rifluoromethoxyethoxy)-phenyl]-3-(2,6-difluoro-benzoyl)urea], a relatively new benzoylphenyl urea insect growth regulator which inhibits the chitin formation on larvae of various insects (Lepidoptera, Coleoptera, Homoptera and Diptera) (Tomlin, 1997). Tropical soils and climates are different from those of the temperate regions. Thus even if the degradation of pesticides on temperate soils have been studied, these can not be extrapolated to tropical soils. Recently, we have reported the effect of novaluron on microbial biomass, respiration and fluorescein diacetate hydrolyzing activity in tropical soils (Das et al., 2007). In the present work, the research efforts were directed to study the degradation behavior of novaluron in tropical soils under laboratory simulated conditions in the Pesticide Residue Laboratory of Bidhan Chandra Krishi Viswavidyalaya during January, 2006.

\section{MATERIALS AND METHODS}

Details of collection and preparation of alluvial (AL) and coastal saline (CS) soils and their properties were reported in our previous article (Pal et al., 2005).

\section{Experimental materials and plan}

Novaluron (99.5\% pure) was applied to the soils at field rate (FR), 2 times FR (2 FR) and 10 times FR (10 FR). Pesticide degradation was studied in aerobic state for both non-sterile and sterile conditions under dark in triplicate for each soil type in every sampling time point. Each conical flask fitted with nonabsorbent cotton plug containing $50 \mathrm{~g}$ soil was sterilized by autoclaving on three consecutive days at $121^{\circ} \mathrm{C}$ for 20 min. (Sukul and Spiteller, 2001) and the sterile condition was maintained throughout the study period. Sterility of the soil was affirmed periodically by microbiological plating technique (Trevors, 1996). The moisture content of the soil was maintained with the aseptic addition of the requisite quantity of sterile distilled water. The incubation study was carried out at $60 \%$ water holding capacity (WHC) of soil at $30{ }^{\circ} \mathrm{C}$ for 90 days in an incubator. The two higher rates, 2 FR and $10 \mathrm{FR}$, were employed to minimize the influence of adsorption of novaluron on soil particles.

\section{Novaluron treatment}

The conversion of the field application to mg of pesticide per $\mathrm{kg}$ of soil was made assuming an even distribution of the pesticide compound in the $0-15 \mathrm{~cm}$ layer. Based on the conversion by the use of the parameters (soil depth $15 \mathrm{~cm}$ and soil density 1.5 $\mathrm{g} / \mathrm{cm}^{3}$ ) the FR corresponds to a weighed amount of $0.017 \mathrm{mg}$ novaluron per $\mathrm{kg}$ soil (dry weight). The calculated amount of sterile (passed through $0.2 \mu \mathrm{m}$ membrane filter paper) solution of novaluron in $1 \mathrm{~mL}$ methanol was applied to $50 \mathrm{~g}$ soil in individual amber coloured Erlenmeyer flasks $(250 \mathrm{~mL})$ plugged with cotton pad. After complete removal of methanol by evaporation at room temperature, the flasks were incubated at $30^{\circ} \mathrm{C}$ for the periodic incubation study. The control samples received only methanol and underwent the same procedure.

\section{Determination of novaluron residues}

50 g Samples were extracted with $100 \mathrm{~mL}$ of acetonitrile: water $(65: 35)$ using a mechanical shaker and filtered through a Buchner funnel after washing using $100 \mathrm{~mL}$ of the extracting solvent. The acetonitrile was evaporated by a rotary vacuum evaporator at $40{ }^{\circ} \mathrm{C}$. The concentrated extract was transferred to a separating funnel with distilled water $(100 \mathrm{~mL})$. Clean up was carried out by liquid-liquid partitioning with dichloromethane. The dichloromethane fraction was concentrated under 
vacuum followed by partitioning with hexane: acetonitrile (1:2), the hexane fractions being discarded. The concentrated acetonitrile fraction was further cleaned up by column chromatography using activated silica gel in between two layers of sodium sulphate. Hexane: acetone $(8: 2)$ was used to elute novaluron from the column. The organic fraction was evaporated to dryness, rinsed with HPLC grade methanol and filtered $(0.2 \mu \mathrm{m})$ for HPLC analysis. High Performance Liquid Chromatograph (HPLC 1050 Hewlett Packard equipped with UV detector and Chemito 5000 Data Processor) was used for final determination of novaluron residues. Shandon Hypersil $250 \times 4.6 \mathrm{~mm}$ ODS $5 \mu \mathrm{m}\left(\mathrm{RPC}_{18}\right)$ column was used for the chromatographic separation of novaluron. The mobile phase consisted of methanol/ water $80 / 20(\mathrm{v} / \mathrm{v})$ and the flow-rate was $1 \mathrm{~mL} / \mathrm{min}$. Quantification was performed against novaluron standard at a wavelength of $254 \mathrm{~nm}$. Under this condition the retention time of novaluron was $3.6 \mathrm{~min}$. and the method detection limit was $0.01 \mathrm{mg} / \mathrm{kg}$. The average recovery was $89.6-91.3 \%$ for novaluron from both types of soils. Determination of novaluron residues in the treated samples was carried out as per the recovery study.

\section{RESULTS AND DISCUSSION}

Degradation of novaluron has been studied in sterilized and nonsterilized AL and CS-soils under laboratory condition and the results are presented in Tables 1 and 2. Novaluron degradation took place in sterilized soils indicating the role of chemical and other abiotic factors other than photodegradation as the soils

Table 1: Regression equation, degradation rate constant $(\mathrm{k})$, correlation coefficient $\left(r^{2}\right)$ and half-life $\left(t_{1 / 2}\right)$ values of novaluron in alluvial and coastal saline soils under non-sterile and sterile condition

\begin{tabular}{|c|c|c|c|c|c|}
\hline Treatment & $\begin{array}{c}\text { Non- } \\
\text { sterilized / } \\
\text { sterilized }\end{array}$ & $\begin{array}{l}\text { Regression } \\
\text { equation }\end{array}$ & $\mathrm{k} /$ day & $r^{2}$ & $\begin{array}{c}t_{1 / 2} \\
\text { (day) }\end{array}$ \\
\hline \multicolumn{6}{|l|}{ Alluvial soil } \\
\hline Novaluron FR & \multirow{3}{*}{$\begin{array}{l}\text { Non- } \\
\text { sterile }\end{array}$} & $y=1.1804-0.0177 x$ & 0.0177 & 0.98 & 17.0 \\
\hline Novaluron 2 FR & & $y=1.5031-0.0172 x$ & 0.0172 & 0.96 & 17.5 \\
\hline Novaluron $10 \mathrm{FR}$ & & $y=2.2942-0.0169 x$ & 0.0169 & 0.93 & 17.8 \\
\hline Novaluron FR & \multirow{3}{*}{$\begin{array}{l}\text { Sterile } \\
\text { il }\end{array}$} & $\mathrm{y}=1.2264-0.0056 \mathrm{x}$ & 0.0056 & 0.98 & 53.7 \\
\hline Novaluron 2 FR & & $y=1.5456-0.0055 x$ & 0.0055 & 0.96 & 54.7 \\
\hline $\begin{array}{l}\text { Novaluron } 10 \mathrm{FR} \\
\text { Coastal saline soil }\end{array}$ & & $y=2.2279-0.0051 x$ & 0.0051 & 0.98 & 59.0 \\
\hline Novaluron FR & \multirow{4}{*}{$\begin{array}{l}\text { Non- } \\
\text { sterile }\end{array}$} & $y=1.2094-0.0264 x$ & 0.0264 & 0.99 & 11.4 \\
\hline Novaluron 2 FR & & $y=1.5217-0.0262 x$ & 0.0262 & 0.99 & 11.5 \\
\hline Novaluron $10 \mathrm{FR}$ & & $\mathrm{y}=2.2044-0.0237 \mathrm{x}$ & 0.0237 & 0.99 & 12.7 \\
\hline Novaluron FR & & $y=1.2177-0.0104 x$ & 0.0104 & 0.98 & 28.9 \\
\hline Novaluron 2 FR & \multirow[t]{2}{*}{ Sterile } & $y=1.5142-0.0103 x$ & 0.0103 & 0.97 & 29.2 \\
\hline Novaluron $10 \mathrm{FR}$ & & $y=2.2160-0.0101 x$ & 0.0101 & 0.99 & 29.8 \\
\hline
\end{tabular}

were kept in dark during the experimental period. In nonsterilized soils novaluron degradation was found higher than that in sterilized soils suggesting the possible role of microbes. However, there could be the possibility of bonding to humic substances or entrapment due to sequestration reactions of the compound not recovered by the extraction method. Generally, reversible or irreversible sorption and/or sequestration mechanisms in combination with the microbially driven turnover of soil organic matter strongly influence pesticide metabolism although the key processes involved are still not understood precisely (Burauel and Führ, 2001). The initial deposits of novaluron at zero day ( $2 \mathrm{~h}$. after spiking) in non-sterilized soils ranged from $0.0163-0.1640$ $\mathrm{mg} / \mathrm{kg}$ (AL-soil) and $0.0166-0.1643 \mathrm{mg} / \mathrm{kg}$ (CS-soil) while the same values for sterilized soils were $0.0164-0.1638$ $\mathrm{mg} / \mathrm{kg}$ (AL-soil) and $0.0167-0.1644 \mathrm{mg} / \mathrm{kg}$ (CS-soil) for the different novaluron applications rates (table not presented). The novaluron residue in non-sterilized AL and CS-soils persisted for 45 to 90 days and in sterilized soils for 90 days. The degradation pattern of novaluron (at FR, 2FR and 10FR) for both the soil types (e.g., AL and CS) under non-sterile and sterile conditions has been presented in Fig. 2.

The half-life values, calculated from the best-fit lines of the logarithm of residual concentrations versus incubation period, suggested first order reaction kinetics for novaluron degradation in both sterilized and nonsterilized AL and CS-soils. The half-life values (Table 1) ranged from 17.0-59.0 days (AL-soil) and 11.4-29.8 days (CS-soil) according to the novaluron application rates to soils. The half-lives of novaluron in non-sterilized soils ranged from 17.0 - 17.8 days (AL-soil) and 11.412.7 days (CS-soil).

Table 2: Comparative role of biotic and abiotic factors on novaluron degradation in alluvial and coastal saline soils at day 45 under laboratory condition

\begin{tabular}{|c|c|c|c|}
\hline \multirow[b]{2}{*}{ Treatment } & \multicolumn{3}{|c|}{ Percent degradation } \\
\hline & $\begin{array}{c}\text { Non-sterilized } \\
\qquad \text { (Biotic }+ \\
\text { Abiotic) }\end{array}$ & $\begin{array}{l}\text { Sterilized } \\
\text { (Abiotic) }\end{array}$ & Biotic \\
\hline \multicolumn{4}{|l|}{ Alluvial soil } \\
\hline Novaluron FR & 82.37 & 36.18 & 46.19 \\
\hline Novaluron 2FR & 79.53 & 36.27 & 43.26 \\
\hline \multicolumn{3}{|c|}{ Coastal saline soil } & 33.39 \\
\hline Novaluron FR & 93.17 & 65.31 & 27.86 \\
\hline Novaluron 2FR & 93.39 & 65.27 & 28.12 \\
\hline Novaluron 10FR & 90.17 & 64.66 & 25.51 \\
\hline
\end{tabular}


Novaluron degradation in soil
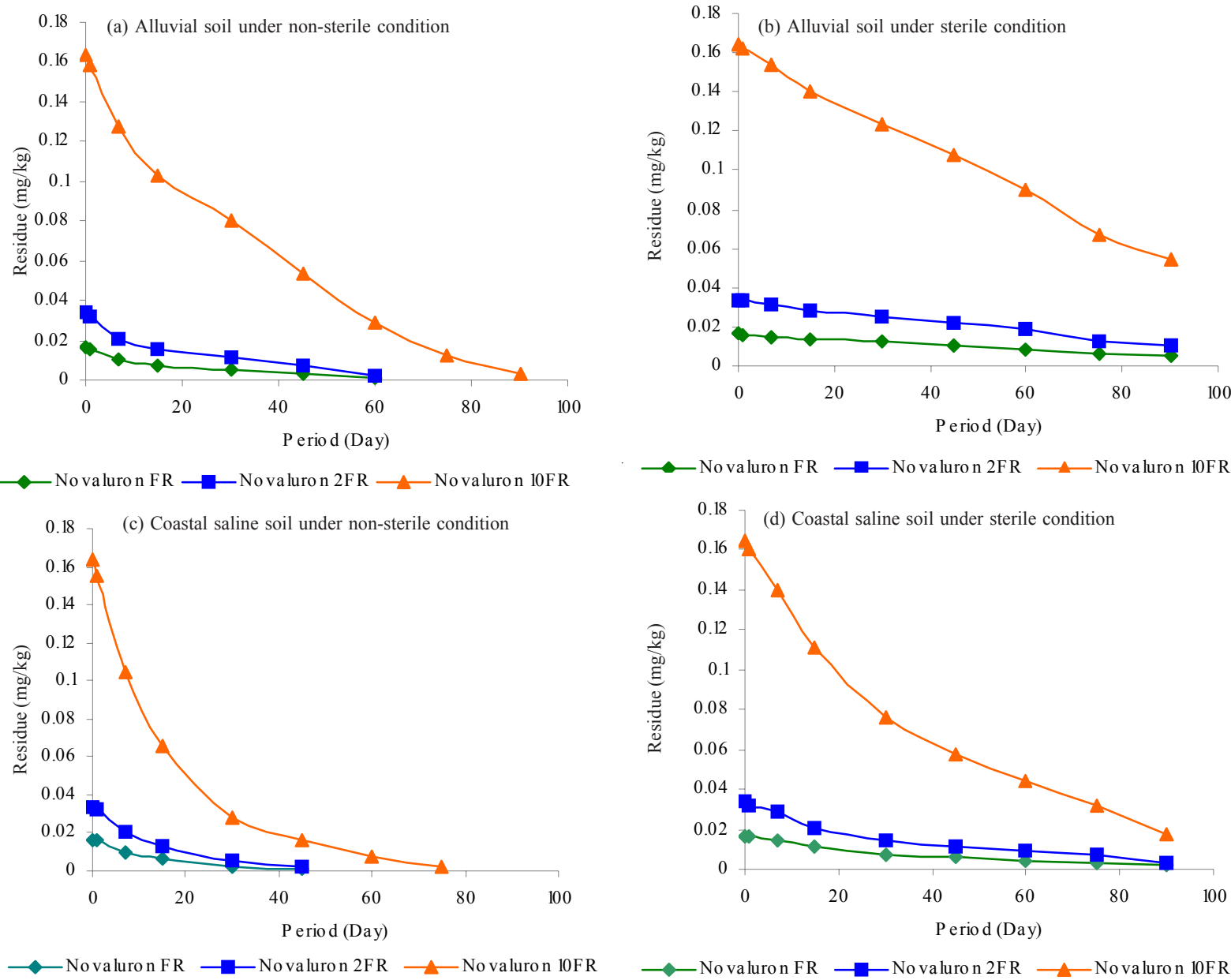

Fig. 2: Degradation of novaluron at three different application rates in alluvial and costal saline soils under sterile and nonsterile conditions

The same values for sterilized soils were $53.7-59.0$ days (AL-soil) and 28.9 - 29.8 days (CS- soil) respectively. The degradation rate constants (k/day) (obtained from the slope value of the first order equation) of novaluron in non-sterilized AL-soil was found to vary from 0.0169 to 0.0177 while $\mathrm{k}$ for the CS- soil between 0.0237 and 0.0264 (Table 1). The same for sterilized condition ranged between 0.0051 and 0.0056 in AL-soil and 0.0101 to 0.0104 in CS soil. Higher the application rates of novaluron lower were the degradation rate constants. This corroborates with the findings (Prakash et al., 2000; Yu et al., 2003; Pal et al., 2006b) of lower degradation rate constant of the herbicide butachlor with increasing application rates. The reduced degradation rates at higher initial concentrations in the present study could be attributed to limitation in the number of reaction sites in soil and toxic effects on microorganisms or enzyme inhibition (Prakash et al., 2000). Comparative role of biotic and abiotic factors to novaluron degradation in soils is presented in Table 2. Abiotic factors contributed 33.92-36.27\% (AL-soil) and $64.66-65.31 \%$ (CS-soil) to the degradation of novaluron. On the other hand, 33.39-46.19\% (AL-soil) and $25.51-28.12 \%$ (CS-soil) degradation was due to the influence of microbial activity. Present study demonstrated that the abiotic factors strongly influenced the degradation of novaluron. Pencycuron of similar molecular nature showed similar trend in saline environment than in non-saline environment ( $\mathrm{Pal}$ et al., 2005). Biotic factors caused greater degradation in ALsoil compared to CS-soil. Microbial biomass and its activity are less in the coastal saline soil than in nonsaline soil ( $\mathrm{Pal}$ et al., 2005), which could be the reason for this observation. 


\section{ACKNOWLEDGEMENTS}

The author is grateful to Department of Agricultural Chemicals, Bidhan Chandra Krishi Viswavidyalaya, India for excellent technical assistance and Indofil Chemicals Company, Mumbai, India for sponsoring the research project.

\section{REFERENCES}

Adhya, T. K.; Wahid, P. A.; Sethunathan, N., (1987). Persistence and biodegradation of selected organiphosphorous insecticides in flooded versus non-flooded soils. Biol. Fertil. Soils, 4 (1-2), 36-40.

Banerjee, A.; Padhi, S.; Adhya, T. K., (1999). Persistence and biodegradation of vinclozolin in tropical rice soils. Pest. Sci., 55 (12), 1177-1181.

Beigel, C.; Charnay, M. P.; Barriuso, E., (1999). Degradation of formulated and unformulated triticonazole fungicide in soil: effect of application rate. Soil Biol. Biochem., 31 (4), 525-534.

Burauel, P.; Führ, F., (2001). Long-term fate of organic chemicals in lysimeter experiments and the role of the bound pesticide fraction. In C.E. Clapp, M.H.B. Hayes, N. Senesi, P.R. Bloom and P.M. Jardine (Eds.), Humic Substances and Chemical Contaminants. Madison, USA: Soil Science Society of America. 289-301.

Das, P.; Pal, R.; Chowdhury, A., (2007). Effect of novaluron on microbial biomass, respiration and fluorescein diacetate hydrolyzing activity in tropical soils. Biol. Fertil. Soils, 44 (2), 387-391.

Hafez, H. F. H.; Thiemann, W. H. P., (2003). Persistence and biodegradation of diazinone and imidacloprid in soil. Proc. XII Symp. Pest. Chem., Congress Centre Università Cattolica, Via Emilia Parmense 84, Piacenza. 35-42.

Karpouzas, D. G.; Walker, A.; Williams, R. J. F.; Drennan, D. S., (1999). Evidence for the enhanced biodegradation of ethoprophos and carbofuran in soils from Greece and the UK. Pest. Sci., 55 (3), 301-311.
Pal, R.; Chakrabarti, K.; Chakraborty, A.; Chowdhury, A., (2005). Degradation of Pencycuron in soil: Effect of application rate and soil conditions. Pest Manag. Sci., 61 (12), 1220-1223.

Pal, R.; Chakrabarti, K.; Chakraborty, A.; Chowdhury, A. (2006a). Degradation and effects of pesticides on soil microbiological parameters - a review. Int. J. Ag. Res., 1 (3), 240-258.

Pal, R.; Das, P.; Chakrabarti, K.; Chakraborty, A.; Chowdhury, A., (2006b). Butachlor degradation in tropical soils: Effect of application rate, biotic-abiotic interactions and soil conditions. J. Environ. Sci. Health, B41 (7), 1103-1113.

Prakash, N. B.; Suseela Devi, L., (2000). Persistence of butachlor in soils under different moisture regime. J. Ind. Soc. Soil Sci., 48 (2), 249-256.

Racke, K. D.; Skidmore, M. W.; Hamilton, D. J.; Unsworth, J. B.; Miyamoto, J.; Cohen, S. Z., (1997). Pesticide fate in tropical soils. Pure and Appl. Chem., 69 (6), 1349-1371.

Sannino, F.; Filazzola, M. T.; Violante, A.; Gianfreda, L., (1999). Fate of herbicides influenced by biotic and abiotic interactions. Chemosphere, 39 (2), 333-341.

Singh, S. P., (2000). Survey of Indian Agriculture 2000. In The Hindu. pp. $159-163$.

Sommerville, L., (1987). Perspective on side effect testing. In L. Sommerville and M.P. Greaves (Eds.), Pesticide Effects on Soil Microflora. London: Taylor and Francis, 5-13.

Sukul, P.; Spiteller, M., (2001). Influence of biotic and abiotic factors on dissipating metalaxyl in soil. Chemosphere, 45 (6-7), 941-947.

Tomlin C. D. S., (1997). Novaluron. In The Pesticide Manual, $11^{\text {th }}$, UK: British Crop Protection Council, 888-889.

Trevors, J. T., (1996). Sterilization and inhibition of microbial activity in soil. J. Microbiol. Methods, 26 (1-2), 53-59.

Yu, Y. L.; Chen, Y. X.; Luo, Y. M.; Pan, X. D.; He, Y. F.; Wong, M. H., (2003). Rapid degradation of butachlor in a wheat rhizosphere soil. Chemosphere, 50(6), 771-774.

Zhu, G.; Wu, H.; Guo, J.; Kimaro, F. M. E., (2004). Microbial degradation of fipronil in clay loam soil. Water Air Soil Pollut., 153 (1), 35-44.

\section{AUTHOR (S) BIOSKETCHES}

Das, P., has completed Ph.D. from the Department of Agricultural Chemicals, Bidhan Chandra Krishi Viswavidyalaya, Mohanpur, West Bengal, Pin - 741252, India. Email:piwdas@gmail.com

Pal, R., has completed Ph.D. from the Department of Agricultural Chemistry and Soil Science, University of Calcutta, 35 BallygungeCircular Road, Calcutta, Pin-700019, India. Currently he is postdoctoral research associate in Center for Environmental Risk Assessment and Remediation, University of South Australia, Mawson Lakes Campus, Mawson Lakes Boulevard, Mawson Lakes, SA, Australia, Post Code-5095.

Email:p_raktim@rediffmail.com

Chowdhury, A., is Professor of Agricultural Chemistry in the Department of Agricultural Chemistry and Soil Science, University of Calcutta, 35 Ballygunge Circular Road, Calcutta, Pin-700019, India. Email:ashimkly@hotmail.com 